\title{
Econometric analysis of Australian emissions markets and electricity prices
}

\author{
Deborah Cotton $^{a}$, \\ Lurion De Mello ${ }^{b}$, \\ ${ }^{a}$ * Corresponding author; University of Technology, Sydney \\ P.O. Box 123, Broadway NSW 2007 Australia \\ Deborah.cotton@uts.edu.au
}

Phone: +612 95147740

${ }^{\mathrm{b}}$ Macquarie University, Sydney 2109, Australia

\section{Introduction}

A major goal of financial markets is to ensure the efficient flow of funds between surplus units and deficit units. This should be achieved in a timely and cost effective manner so that those who can most efficiently use the funds will have access them. There has been a great deal of research conducted on different measures of market efficiency since Fama's study in 1970. While there are findings of anomalies Fama (1998) suggests that these are fragile and may disappear depending on which method of measurement is used. Fama states in the introduction to his 1970 paper that "the ideal is a market in which prices provide accurate signals for resource allocation: that is, a market in which firms can make productioninvestment decisions” (Fama, 1970, p383). Emissions trading schemes (ETSs) trade in a context where an ideal market is one in which those who can most efficiently reduce their emissions will be able to sell either their own surplus certificates or those they create. The 
overriding goal of emissions trading markets is to achieve a reduction in $\mathrm{CO}_{2}-\mathrm{e}^{1}$ in the most cost effective way. Garnaut (2011, Chapter 11) stated that "Under a carbon price, the market, rather than the government, will be making abatement decisions, which will ensure emissions reductions are delivered at lowest cost.”

The question of whether or not a market has been efficient may be approached in two main ways. One way is to measure whether compliance has been achieved. The markets under analysis in this paper are the two largest and most actively traded emissions trading schemes in Australia during the period under analysis, January 2004 to December 2010. These are the New South Wales Greenhouse Gas Abatement Scheme (GGAS) and the Mandatory Renewable Energy Trading Scheme (MRET). The GGAS was closed in 2012 upon the commencement of the Federal Labor Government's carbon tax in order to reduce duplication. The MRET was split into two separate components in January 2011, the Large-scale Renewable Energy Target (LRET) and the Small-scale Renewable Energy Scheme (SRES). Using the level of compliance that has been achieved as the measure, it can be concluded that the markets were efficient. The legislated $\mathrm{CO}_{2}$-e reductions required under each scheme were achieved to a level of around 99\% for the years under review in this paper. The other way of measuring efficiency is by determining if the schemes have had a price effect on the markets with which they have had the greatest connection. This paper aims to separate ETSs from other policies and determine if the markets themselves have contributed to a reduction in emissions in Australia. This paper will test this by determining if the ETS prices have had an effect on the wholesale price of electricity.

The electricity sector is chosen predominantly because this sector is the target for the MRET, the largest and most frequently traded ETS in Australia. The MRET goal is to encourage

\footnotetext{
${ }^{1} \mathrm{~A}$ tonne of $\mathrm{CO}_{2}$-e is a quantity of any greenhouse gas which has the same warming effect as a tonne of $\mathrm{CO}_{2}$.
} 
additional generation of electricity from renewable energy resources thereby reducing greenhouse gas emissions. This increased demand for these renewable energy sources would then assist in ensuring that renewable energy sources are ecologically and financially sustainable. The effect of price changes for renewable energy certificates, the certificates used in the MRET, are therefore most likely to be found in wholesale electricity prices. The expectation is that, as electricity producers move to using more renewable energy sources, the wholesale electricity price will increase. This is because the costs, as described in Figure 2 and explained later, indicate that using renewable energy sources is more expensive than using coal for the production of electricity. Therefore if the MRET is causing this change in energy source, the electricity price should increase. The GGAS does not have as clear a link as the MRET to electricity prices but there remains an expectation that if it is working efficiently, it too would affect the electricity prices. The goal of the GGAS is to reduce greenhouse gas emissions through the use of benchmarks. The major participants in this scheme include retail suppliers, electricity generators and other suppliers of electricity to a customer and market customers. Additionally, certificate creation involved activities including those which reduce the consumption of electricity and production of electricity which results in reduced greenhouse gas emissions. In a similar way to the MRET we anticipate that if the GGAS is contributing to a change in the energy sources used for electricity generation, then the cost of wholesale electricity would increase.

The electricity sector is by far the largest emissions sector in Australia, with annual emissions increasing by $49.1 \%$ from 1990 to 2011 as discussed in the Australian National Greenhouse Gas Accounts National Inventory Report 2010 (Australian Government, 2012a). Under the Kyoto Protocol, ratified by Australia in 2007, the allowed emissions for Australia were set at $108 \%$ of 1990 levels. While the electricity sector accounts for only a part of these allowable 
emissions, it produced 35\% of Australia’s emissions for the year to March 2012 (Australian Government, 2012a). After peaking in 2008-09 at 207.9 $\mathrm{Mt} \mathrm{CO}_{2}-\mathrm{e}$, emissions in the sector fell to $193.1 \mathrm{Mt} \mathrm{CO}_{2}$-e in 2011 (Australian Government, 2012b). The electricity sector involves electricity generation from fuel combustion and renewable sources such as wind and solar. We aim to establish whether emissions trading markets have had a long-term effect on wholesale electricity prices in the sector. In particular we want to determine causality. We have used a generalised forecast error variance decomposition (GVD) and generalised impulse response function analysis (GIRF) to determine this. These models are explained fully in our methodology and results in Section 4.

The growing global demand for energy has been beneficial for the Australian economy, due to the country's abundant coal, uranium and gas deposits. In 2012 Australia was the world's ninth-largest energy producer (Enerdata, 2013). Australia’s electricity generation is dominated by fossil fuels with $430 \mathrm{Mt}$ coal and lignite being produced in 2012. Coal exports earned \$38,581million for the year to June, 2013 which accounted for 15.6\% of Australia’s exports for the year (ABS), 2013). Coals are the highest $\mathrm{CO}_{2}$-e emitters of all energy sources and contributed around 79.2\% of electricity generation in March 2012 (Australian Government, 2012a). The mining lobby is a very strong force in Australia, with coal mining employing around 229,100 full-time and 9,600 part-time workers and contributing to the strength of many rural communities. Under current production levels, black coal has estimated economic demonstrated reserves of 111 years with brown coal at 539 years. Australia is the fourth-highest coal and lignite producer in the world and production increased at an average of $2.9 \%$ p.a. from 2000 to 2012. While the percentage of renewable energy used as a fuel source for electricity generation has increased, Figure 1 shows that this is still a very small proportion coming from a very low base. 


\section{Figure 1. Electricity Generation by Fuel Source}

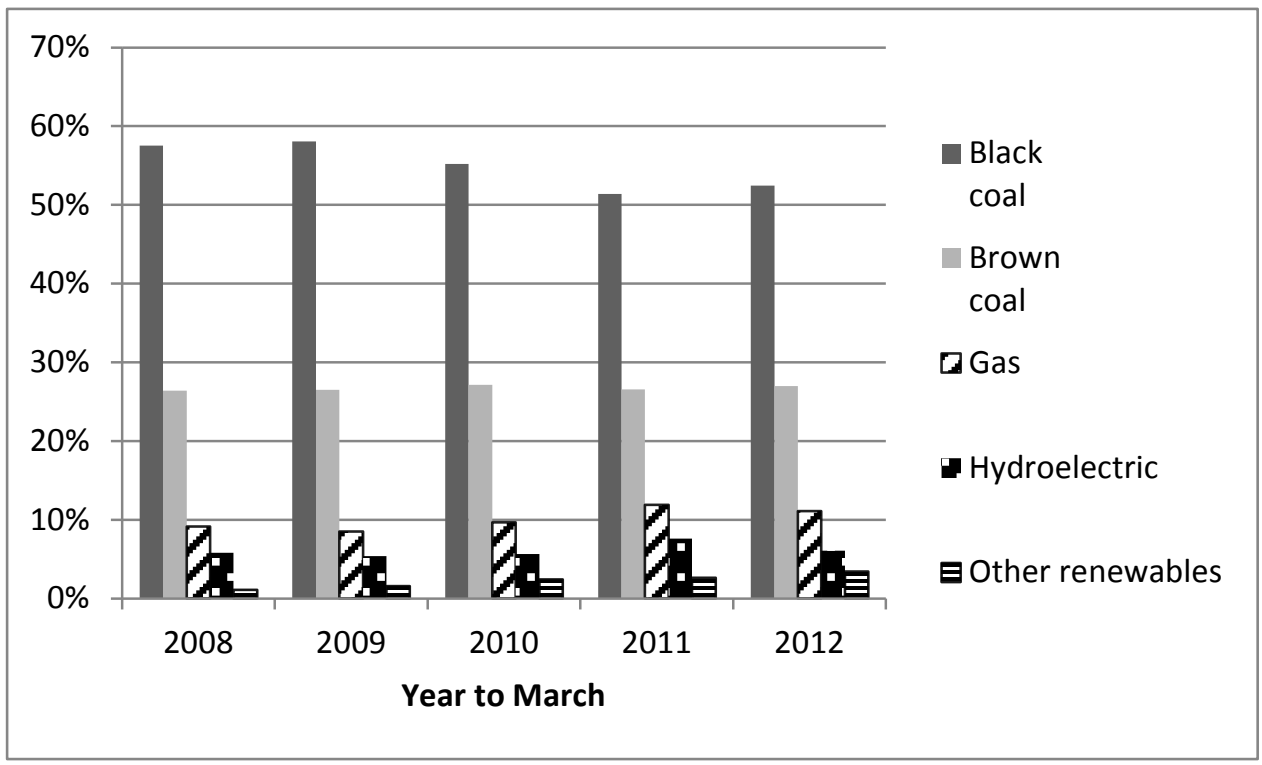

Source: Australian Government, Energy in Australia 2011

In dollar terms, coal is the cheapest fuel source in Australia and is likely to remain so for many years to come. Australian Energy Technology Assessment (2012) showed the levelised cost of energy by technology in Australian dollars per megawatt-hour (MWh) to be approximately in the ranges shown in Figure 2 below.

Figure 2: Levelised Cost of Energy by Technology in \$AUD per MWh in 2012

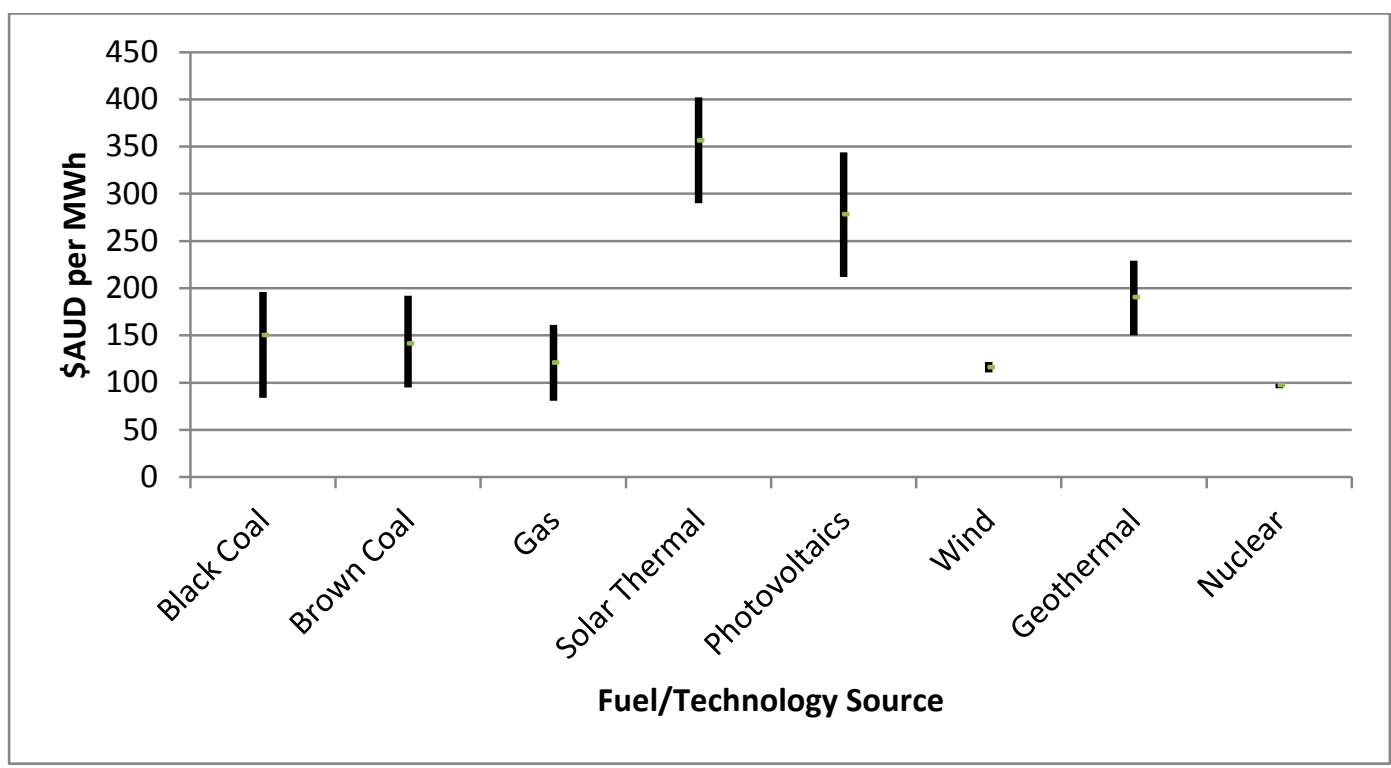

Source: Bureau of Resources and Energy Economics, Australian Government (2012) 
Black Coal = supercritical pulverised black coal; with and without carbon capture and storage

Brown Coal = supercritical pulverised brown coal; with and without carbon capture and storage

Gas = combined cycle gas turbine; range includes south western interconnector system scale and with carbon capture and storage

Solar Thermal = solar thermal parabolic trough; range includes with storage, central receiver and central receiver with storage

Photovoltaics = range includes; non-tracking, single axis tracking and dual axis tracking

Wind $=$ on shore

Geothermal $=$ range includes hot sedimentary aquifer and hot rock

Nuclear $=$ Gen $3+$

The ETS endeavours to incorporate into the costs of production an amount attributable to the $\mathrm{CO}_{2}$-e emissions that occur in generating electricity from non-renewable resources. It does this by reducing the amount of emissions allowed before penalties apply, and creating a market where the surplus and deficit units of the certificates can trade with each other. If this is done efficiently we would initially expect the cost of electricity to increase due to the additional costs for producers. This will occur as they move towards renewable, more expensive sources of energy and away from the cheaper, high emitting fuels. It will also occur due to the increase in the cost of coal which will result from the additional cost to producers of purchasing emissions certificates. Over time renewable energy production is expected to become more efficient, leading to a decrease in costs and hence a decline in the cost of electricity.

The next section of this paper discusses the literature around market efficiency of ETSs with a focus on the use of electricity prices as a measure. It then provides descriptions of the GGAS and MRET in Section 3, along with the data used in our analysis. To our knowledge this paper is the first to use the methodology described in Section 4 for this type of analysis. This section also describes the results obtained. Finally in Section 5 the conclusions from our analysis are provided.

\section{Materials and Methods}

\subsection{Literature}


Since the inception of the MRET in 2001, the GGAS in 2003 and the EU ETS in 2005, economists and energy specialists alike have been analysing the markets for their effects and efficiency. Nelson et al. (2012) undertook a literature review of economic studies on carbon pricing with an emphasis on their relationship with electricity prices in Australia. Their review, predominantly of studies done by economic modelling firms, found them to be inconsistent in their estimations of cost pass-through. If the Australian emissions trading schemes are affecting the cost of electricity we would expect a clear indication of cost passthrough. They also conducted a review of the literature on the EU ETS. Some of this literature is discussed below. Nelson et.al. (2012) found the level of pass-through in EU ETS to be dependent upon the emissions intensity of the market being studied.

In 2004 Sartzetakis measured the efficiency in emissions markets in a way which included considerations regarding the economic welfare of the society. Sartzetakis concludes that in the majority of situations these considerations are taken into account. However this conclusion is delivered with caution and assumes that efficient allocation of emission permits will always occur and that bureaucratic mechanisms may be more socially beneficial. Neuhoff et al. (2006) found the allocation of certificates in the EU ETS to have had a big impact on market efficiency, with planning for future allocations distorting current behaviour. This is of interest for this paper as it may provide some explanation of the results of our analysis. There have been many studies undertaken, predominantly in Europe, on the relationship between carbon prices, as measured by the prices of the various emissions trading certificates, and the price of electricity (Bunn and Fezzi, 2007; 2009). Other papers have included $\mathrm{CO}_{2}$ in the policy mix (Keppler and Mansanet-Bataller, 2010) and the stock market (Oberndorfer, 2009). These papers provide the basis for our analysis.

Market imperfections were felt to have aggravated the effect of the European ETS on electricity prices. Honkatukia et al. (2006) found that around 75\% to $85 \%$ of wholesale 
electricity price changes were passed on to the Finnish spot electricity price. Sjim et al. (2006) found cost pass-through to electricity prices in Germany using ordinary least squares (OLS) and autoregressive model of order 1(AR(1)). As both of these methods may be inconclusive when autocorrelations are present, the analysis was later refined by Zachmann and von Hirschhausen (2008) by using an error correction model (ECM) and an autoregressive, distributed lag model. They found an asymmetric cost pass-through between European allowances and wholesale electricity prices in Germany. The relationship for price rises was found to be stronger than for falls, indicating that increasing costs are more likely to be passed on than reductions. In 2013 Jouvet and Solier used a first order autoregressive model to determine the cost pass-through of $\mathrm{CO}_{2}$ to marginal electricity spot prices in Europe. They found the financial crisis affected the evidence during the second phase of the EU ETS. Their paper indicated power producers did not pass through the cost of carbon during 2009, but in some countries there was evidence of it occurring during the 2010-11 compliance year. Kara et al. (2008) used the VTT electricity market model and the TIMES energy system model and found that nuclear energy could limit the effect of carbon prices on electricity prices.

Bunn and Fezzi (2009) used a structural cointegrated vector error correction model (VECM) and found the carbon price to be an important and exogenous indicator of the electricity price in the United Kingdom. This method does not make a priori assumptions about exogeneity. This method was also used by Freitas and da Silva (2013) in a study of the effect of the second phase of the EU ETS on the Portuguese electricity system. Their analysis found carbon prices played an important role in the equilibrium price of electricity in the long run. In 2011 Cotton and Trück also used cointegration analysis to determine if there was a relationship between wholesale electricity prices and both GGAS and MRET from 2004 to 2010. No relationship was found in the years 2004 to 2007 but this changed to a significant 
relationship in 2007 to 2010. The method used however does not clearly indicate which of the variables are endogenous and which exogenous and so Frietas and da Silva assume electricity is the endogenous variable. Pinho and Madaleno (2011) analysed the effect of nuclear power generation using the VECM and found it could limit the increases in electricity prices as a result of increased carbon prices. This paper and the study by Kara exemplify the importance of the sources of energy in the particular electricity market being studied. More recently Bertrand (2012) used VECM, Granger causality and impulse response functions to analyse the relationship between carbon and energy markets in Phase 2 of the EU ETS. Gas was found to be a driver for carbon prices in equilibrium; however their results in the short run were ambiguous. This paper aims to rectify some of the problems in these earlier papers by using GIRFs and GVDs to determine the endogeneity and exogeneity of the variables (Koop et al, 1996).

\subsection{The Schemes and Data}

The GGAS covered emissions in the state of New South Wales (NSW). Its main goal was to reduce greenhouse gas emissions associated with the production and use of electricity. Due to changes in the federal government carbon reduction policies this scheme ceased operation in July, 2012. NSW has 42\% of Australia’s economically viable black coal resources and consumed around $26.7 \%$ of Australia's energy in 2011-12. The state is therefore a large contributor to the country's emissions. The scheme’s benchmark participants included all NSW electricity retail suppliers, electricity generators who supply directly to large customers in NSW, and large market customers. There are also other companies who use over 100 gigawatt hours (GWh) who became benchmark participants. The NSW Electricity Supply Amendment (Greenhouse Gas Emission Reduction) Act 2002 set a state greenhouse gas benchmark level on a per capita basis, commencing at a level of 8.65 tonnes of $\mathrm{CO}_{2}$-e that has since reduced to 7.27 tonnes where it was set to remain until 2021. The NSW pool 
coefficient indicates the average emissions intensity associated with electricity sourced from the NSW grid and represents $\mathrm{CO}_{2}$-e per MWh of electricity supplied from the pool of the major power stations that are the benchmark participants. These benchmark participants are liable to meet their shares of these emissions. If they exceed their allowed level of $\mathrm{CO}_{2}$-e they must purchase certificates or pay a fine. Certificates may be created by reducing the greenhouse gas intensity of their generated electricity, reducing consumption, forest management for carbon sequestration ${ }^{2}$ or reduction of onsite emissions due to industrial processes. Compliance was maintained at $97 \%$ and above after 2003 with the majority of non-compliance being made up in the following year. Daley and Edis (2011) state that this scheme delivered a greater level of reductions in $\mathrm{Mt} \mathrm{CO}_{2}$-e than the level required by the legislation for the period 2003 to 2011.

The MRET has been the only national scheme operating in Australia with the main goal of encouraging additional electricity generation from renewable sources. Its goal was to reach a level of 9,500 GWh extra renewable energy by 2010 (Department of Climate Change and Energy Efficiency, 2011). The Federal Labor Government proposed a cap and trade emissions trading scheme to be introduced on 1 July, 2014 to replace its new carbon price, which commenced in July 2012. If this proposal is adopted it will allow early linkages to international carbon markets. Under the MRET power generators and wholesale purchasers of electricity make up the liable parties to the scheme and are required to support the additional electricity generation from renewable sources. Certificates may be created for each whole megawatt-hour (MWh) of electricity generated by the power station from renewable sources in excess of the required baseline amount. The baseline is calculated on the amount of energy generated in 1997. Under the Commonwealth’s Renewable Energy (Electricity) Act 2000 Div. 2 S40, the required percentage of renewable energy for the liable parties has

\footnotetext{
${ }^{2}$ Carbon sequestration is the process of carbon capture from the atmosphere and long term storage.
} 
increased from $0.24 \%$ in 2001 to $5.62 \%$ in 2011 . The scheme was expanded to ensure $20 \%$ of Australia's electricity supply comes from renewable energy sources by 2020. Compliance has been over 96\% since the scheme commenced. Similar to the GGAS, fines are incurred for non-compliance. Daley and Edis (2011) show that the MRET scheme, like the GGAS, has

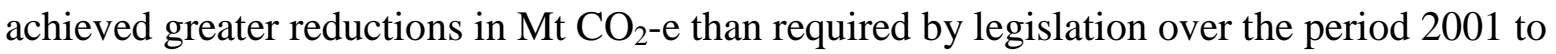
2010.

In 2010 legislation was passed to divide the MRET into two parts in order to improve efficiency for small-scale entities. This change came into effect in the beginning of 2011 and there is now a Large-scale Renewable Energy Target (LRET) and a Small-scale Renewable Energy Scheme (SRES). The LRET continues to use the same mechanism for determining the required number of certificates to be surrendered. The SRES allows liable entities to create certificates based on the amount of energy their small-scale technology produces or displaces. Due to the effect of this split on prices and volumes traded the data used finishes at the end of 2010 for both GGAS and MRET in order to maintain consistency.

These markets have a relatively small number of trades compared with many of the financial markets. They have days where there are multiple trades interspersed with periods of no trades in a day. Early in the schemes' operations there were trading gaps which lasted some weeks. While this is no longer the case, again for consistency reasons, we have used a different approach to obtaining the weekly prices for our analysis and have not commenced the data until the beginning of 2004. Similarly, the futures trades had very light trading, limiting the ability to use it for analysis. Using weekly prices for GGAS and MRET we have obtained 365 observations for each variable. The Australian Financial Markets Association (AFMA) collects market participants' weekly views of the prevailing bid and offer prices for the GGAS certificates (NGACs) and the MRET certificates (RECs). The average of the bid and ask prices has been used. The adjused gas (AGAS) and adjusted electricity (AELEC) 
prices have been obtained from the Australian Energy Market Operator (AEMO). The AEMO is the National Energy Market Operator and planner. The electricity prices are obtained from them as supplied from the National Electricity Market (NEM) which operates as the wholesale market for the supply of electricity to retailers and end-users. This data covers Queensland, New South Wales, the Australian Capital Territory, Victoria, South Australia and Tasmania. The Victorian Wholesale Gas Market data is used as the source for the AGAS in our model as it is the most relevant data obtainable. It was not until September 2010 that the Short Term Trading Market started operation providing data from some other states.

In order to manage the extreme spikes that can be found in data on prices of electricity and gas we have adjusted the prices using a recursive filter algorithm. This was done by replacing all prices beyond the mean by plus or minus three standard deviations with the median of 16 observations around the replaced value. The log of the prices has been used to reduce variability and change the scale so that the elasticity values can be obtained directly from the parameter estimates. The data are divided into two periods. Period one extends from January 2004 to June 2007, and period two from July 2007 to December, 2010. The division and different econometric analysis, as discussed below, enabled us to determine whether there was any change from the results of the effect of carbon prices on electricity prices found by Cotton and Trück (2011) and clearly determine any causality. Figures 3 and 4 below show the NSW Greenhouse Gas Abatement Certificates, the Renewable Energy Certificates, the adjusted Australian electricity price and the adjusted gas price for each of the two time periods. Table 1 provides summary statistics for these variables divided into the two time periods.

Figure 3: Data for time period one from January 2004 to June 2007 


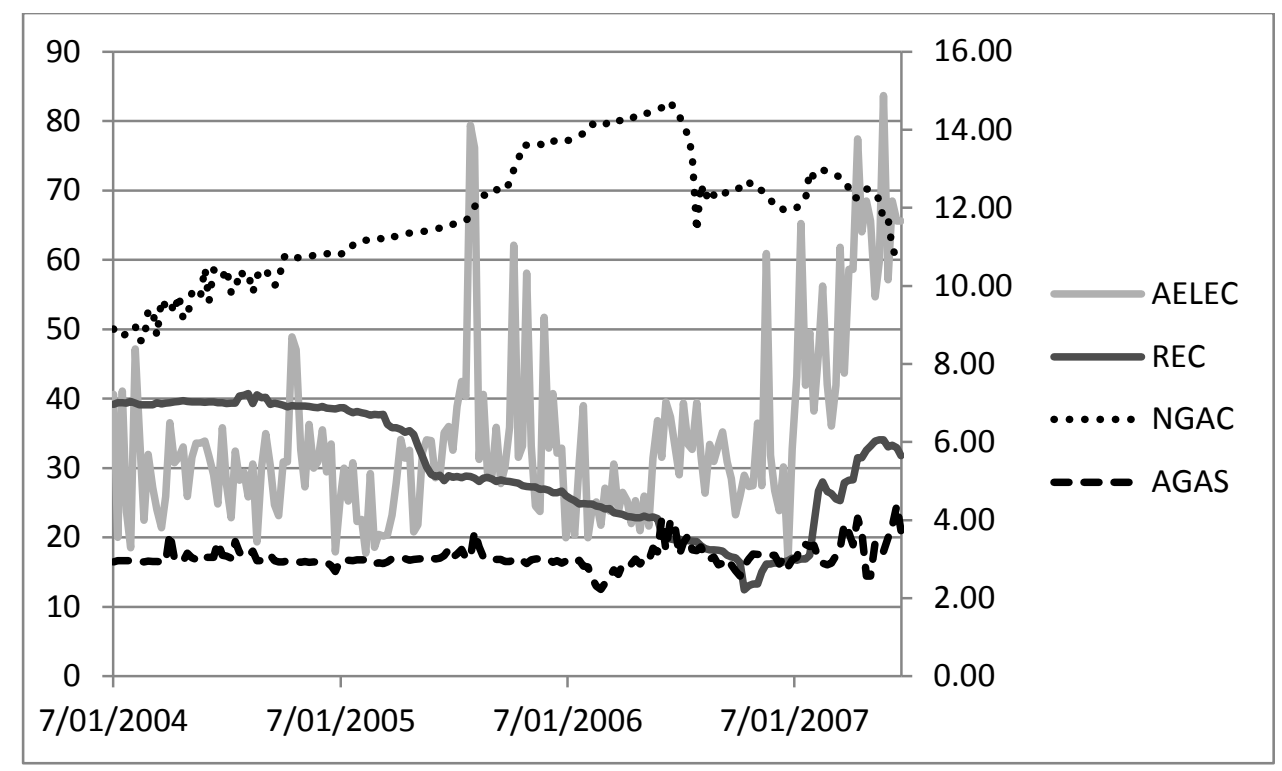

Where: NGAC = NSW Greenhouse Gas Abatement Certificates; AELEC $=$ adjusted Australian wholesale electricity price; AGAS = adjusted gas price; REC = Renewable Energy Certificates

Figure 4: Data for time period 2 from July 2007 to December 2010

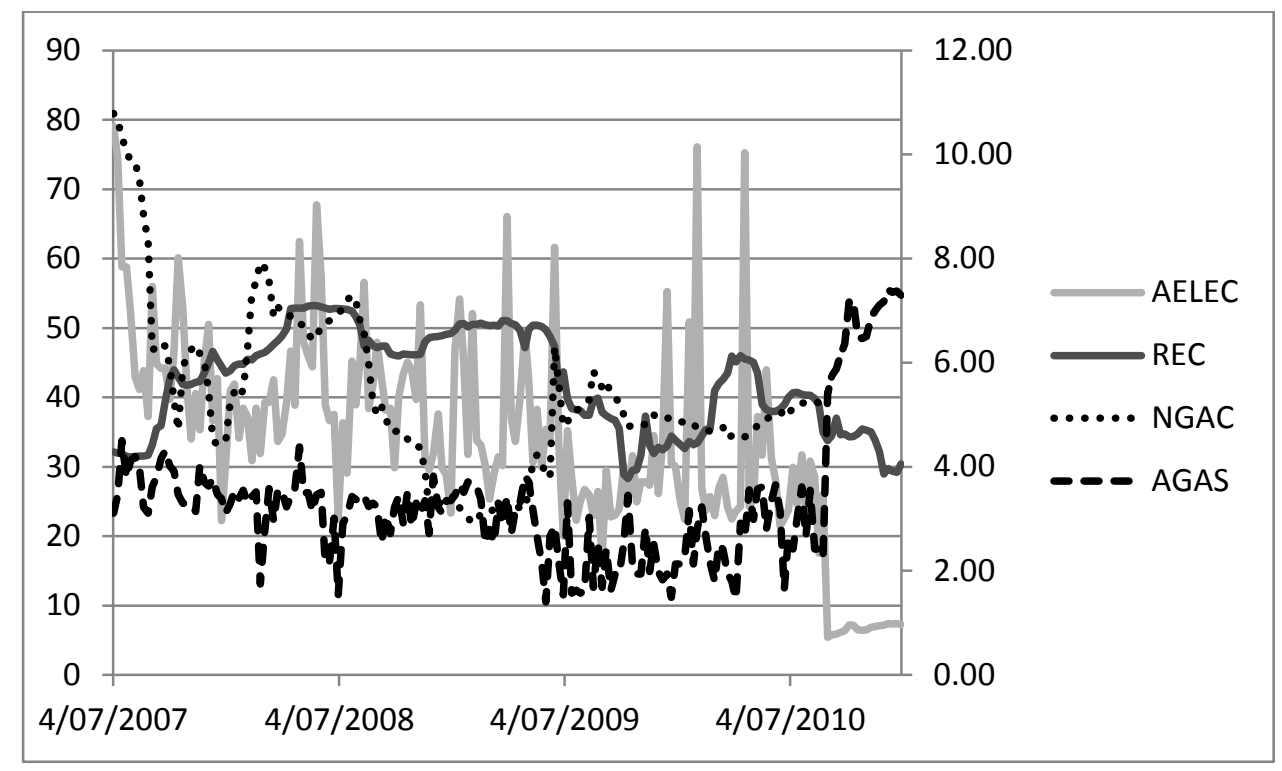

Where: NGAC = NSW Greenhouse Gas Abatement Certificates; AELEC $=$ adjusted Australian wholesale electricity price; AGAS = adjusted gas price; REC = Renewable Energy Certificates 
Table 1:

Summary statistics for the NSW Greenhouse Gas Abatement Certificates, the adjusted Australian electricity price, the adjusted gas price and the Renewable Energy

Certificates

\begin{tabular}{|c|c|c|c|c|}
\hline \multicolumn{5}{|c|}{ Period 1: January 2004 to June 2007 } \\
\hline Variable & NGAC & AELEC & AGAS & REC \\
\hline Median & 11.95 & 31.48 & 2.99 & 28.72 \\
\hline Mean & 11.85 & 34.49 & 3.05 & 29.86 \\
\hline $\begin{array}{c}\text { Standard } \\
\text { Deviation }\end{array}$ & 1.58 & 13.19 & 0.30 & 8.32 \\
\hline Skew & -0.08 & 1.59 & 1.39 & -0.28 \\
\hline $\begin{array}{c}\text { Number of } \\
\text { observations }\end{array}$ & 182 & 182 & 182 & 182 \\
\hline \multicolumn{2}{|c|}{} & & & \\
\hline Variable & NGAC & AELEC & AGAS & REC \\
\hline Median & 5.16 & 33.19 & 3.24 & 43.47 \\
\hline Mean & 5.50 & 33.96 & 3.33 & 42.15 \\
\hline $\begin{array}{c}\text { Standard } \\
\text { Deviation }\end{array}$ & 1.57 & 14.68 & 1.33 & 7.23 \\
\hline $\begin{array}{c}\text { Skew } \\
\text { Number of } \\
\text { observations }\end{array}$ & 0.88 & 0.32 & 1.51 & -0.18 \\
\hline
\end{tabular}

Where: NGAC $=$ NSW Greenhouse Gas Abatement Certificates

AELEC = adjusted Australian wholesale electricity price
AGAS = adjusted gas price
REC = Renewable Energy Certificates

\subsection{Methods}

In this study we check for the hypothesis of a long-term relationship between AELEC,

NGAC, REC and AGAS. We test the impact (if any) of NGAC and REC on the price dynamics of AELEC, and examine whether NGAC played a role or whether it was only REC that had any effect. In order to test this hypothesis, an over-identifying restriction of 'zero' on the NGAC series was imposed based on Pesaran and Shin’s (2002) long-run structural 
modelling technique (LRSM) ${ }^{3}$. LRSM endeavours to estimate theoretically meaningful longrun (or cointegrating) relations by imposing on those long-run relations (and then testing) both identifying and over-identifying restrictions based on theories and a priori information about the economies in which they operate. For testing each restriction one should check the likelihood ratio statistic in each case to establish whether the null hypothesis that there are no restriction/s should be rejected or accepted.

It is well documented that a pre-condition for the application of cointegration and for testing long-run structural relationships is to ensure that all variables are I (1). All our series are nonstationary in their levels form and then become stationary after first differencing. We use the popular ADF, PP and KPSS units root test according to Dickey and Fuller (1979), Phillips and Perron (1988) and Kwiatkowski et al. (1992). Under the ADF and PP test, the series is assumed to be non-stationary and a failure to reject the null hypothesis implies that the series has a unit root. The KPPS test assumes that the series is trend stationary under the null hypothesis, with the alternative being that it is non-stationary. Next, to determine the order of the vector autoregressive model (VAR) we run the unrestricted VAR with eight lags and based on the Akaike Information Criterion (AIC) (Akaike, 1974) we select a VAR (4) for running the restricted VAR based on the Johansen cointegration technique (Johansen and Juselius, 1990; Johansen, 1991). Due to the nature of the data we use the unrestricted intercept and restricted trend model to capture the long-run relationship and the number of cointegrating relationships between the variables. The trace and maximum eigenvalue test indicates a single cointegrating relationship between all the variables. These results were common across both our samples (Jan 2004 - June 2007 and July 2007 - Dec 2010).

\footnotetext{
${ }^{3}$ The LRSM technique can be easily implemented in Microfit 5.0 software (Pesaran, H. and Pesaran B., 2009)
} 
The identification of $\boldsymbol{\beta}$ (in $\Pi_{y}=\alpha_{y} \beta^{\prime}$ ) requires at least $r$ restrictions per each of the $r$ cointegrating relations. ${ }^{4}$ After selecting a single cointegrating relationship $(\mathrm{r}=1)$, we then normalise the AELEC by imposing the non-testable restriction of 1 . This normalising restriction can be applied to the coefficient of any of the integrated variables that enter the cointegrating relation. However, since we are testing the impact of other variables on electricity it was only natural to impose the restriction on AELEC. However, in a more general case where $r>1$, the number of such "normalising” restrictions is just equal to $r$, which needs to be supplemented with a further $r^{2}-r$ a priori restriction.

The LRSM procedure is a subsequent step after we estimate the VECM model and impose the identifying restriction of 1 on the cointegrating vector. Given that we have a model with ( $A E L E C, N G A C, R E C, A G A S$ ) we impose the following over-identifying restriction on the $\boldsymbol{\beta}^{\prime}$. The matrix $\boldsymbol{\beta}^{\prime}$ can be used to impose all the restrictions necessary for the structural long-run relationship to be over-identified. So after normalising, we immediately impose the overidentifying restriction of 'zero' on the NGAC prices to see if the state greenhouse gas abatement scheme had any impact on AELEC.

The likelihood ratio statistic based on the chi-square distribution fails to reject the overidentifying restriction as the test statistic is less than the critical figure at the $95 \%$ confidence level. After this step we estimate the error correction equations of the individual variables, which are summarised below to conserve space.

We have used Granger (1969) causality tests which can be interpreted as within-sample causality tests and can be used to make inferences about causal relationships within the sample period only. In order to have a feel for the relative exogeneity or endogeneity of the variable (or what we call the short-run dynamics) we utilise the GIRFs and GVDs developed

\footnotetext{
${ }^{4}$ Readers interested in more details should consult Pesaran and Shin (2002)
} 
by Pesaran and Shin (2002) and Koop et al. (1996). In the variance decomposition analysis, variance of the forecast error of a particular variable is partitioned into proportions attributable to innovations (or shocks) in each variable in the system, including its own. If a variable can be optimally forecast from its own lags, then it will have all its forecast variance accounted for by its own disturbances (Sims, 1982). The GIRFs examine how the shocks given to the residuals (innovations) of equations within the system of seven equations (one equation for each variable) impact on the variables involved at different time horizons. We use a bootstrap approach to calculate the upper and lower bound based on Pesaran and Pesaran’s (2009) approach.

\section{Results}

For the first sample, January 2004 to June 2007, from the VECM the short-run two-period lag of AELEC are found to be significant in driving changes in AELEC themselves. This is an early sign that AELEC are not affected by changes in other variables in the short run. For the long-run component however, the error correction term is found to be negative and significant $(-0.292, \mathrm{t}=-3.14)$ thus indicating that AELEC are adjusting to their long-run equilibrium from the bottom, but we do not know at this stage exactly which variable is forcing this adjustment. The error correction equation for NGAC also shows that in the short run its price is driven by changes in its one lag price. We also find some weak endogeneity (significance of the error correction term) indicating that some movements in other variables are driving changes in NGAC prices to bring about an adjustment to long-term equilibrium. This might not be surprising as the NGAC was introduced not long prior to the start of the sample period and was not a very liquid instrument with some uncertainty surrounding its price. It could be that the electricity price had some influence on it. The size of the error correction term is found to be small and positive $(0.0216, t=2.27)$ thus showing a small 
adjustment in comparison to AELEC. The positive sign tells us that adjustments are coming from the top meaning the price overshoots and then adjusts back down towards its long-run equilibrium path.

The short-run deviations and the lags of all the variables play no role in the error correction equation for REC except for the first lag of the REC itself. This again tells us that REC is exogenous in the short run and this exogeneity persists in the long run, as indicated by the insignificant $(-0.0069, \mathrm{t}=-0.5047)$ error correction term. The error correction equation for AGAS gives us a similar result in terms of the short-run dynamics but the error correction term is found to be small and positive but significant $(0.062, \mathrm{t}=2.486)$. It could be that gas prices are being driven by changes in electricity and NGAC and REC prices. Again, at this stage we cannot pinpoint exactly the variables that are driving changes in gas prices.

In the second period, July 2007 to December 2010, we find that all the endogeneity present in NGAC and AGAS disappears, REC remains exogenous and AELEC continues to show weak endogeneity. The coefficient of the error correction equation for AELEC is now larger and significant $(-0.557, \mathrm{t}=-5.466)$. This speed of adjustment is almost double that of the pre mid2007 period, telling us that prices are adjusting a lot faster to bring out long-term equilibrium. The wholesale electricity prices are determined by bids from the generators. Those with the lowest prices supply electricity bid first followed by the more expensive bids until the demand is fully met. The price is then determined by the price bid of the marginal supplier in the market. The Australian Industry Group (2011) suggests that the Global Financial Crisis which began in late 2007 to early 2008 depressed demand across the National Electricity Market. At this time there were also extreme weather conditions including drought which greatly reduced the ability of the low-cost generators to supply to the market. Many hydro generators and some coal generators who require large amounts of water were also affected by this, reducing their ability to supply the market. It is likely that these added pressures to 
the market have contributed to a smaller number of suppliers and a speedier impact of costs on the price of wholesale electricity.

The results of the GVDs shown in Table $2 \& 3$ are best interpreted by looking at the diagonal (in bold) where we can see the response of each variable when we introduce a shock to the variance of one of the other variables. The first column tells us the number of weeks we go out of sample to measure the impact of the shock since its inception. If the majority of the shock is self-explained then the variable is deemed to be exogenous. This is an important extension from the error-correction results which is often missed where the significance of the error-correction term only indicates if a variable is weakly endogenous. This means that changes in other variables in the system are driving changes in the endogenous variables. In our VECM result, AELEC are being driven by changes in other variables but we do not know which specific variable is driving those changes. The GVDs give us a better insight into the relative endogeneity of the dynamics. Table 2 shows that the variance in AELEC is selfexplained (93.38\%) when own shocks are introduced in AELEC. As we move further out of sample to week three, approximately $80.26 \%$ of the variance is self-explained with only a fraction being explained by NGAC (2.29\%) and REC (0.67\%). AGAS tend to dominate or cause adjustments in AELEC to bring about long-run equilibrium. As we move further out of sample we can see the progressively increasing role that the variances of AGAS play in driving the variance of AELEC.

NGAC prices seem to play no role whatsoever in the price dynamics and REC seems to play a very minimal role. When we look at 15 and 25 weeks out of sample, nearly $37 \%$ and $43 \%$ of the variance in AELEC is being driven by AGAS. This is not surprising and it has been discussed earlier that the prices are dependent upon the costs incurred by the generators. Gas, as shown in Figure 1, contributes around 10\% to the energy supplied. The NGAC prices initially have a slightly greater effect than REC prices but as we move further out of sample 
RECs seem to have a bigger influence than NGAC prices, where, for example, after 25 weeks approximately $3.5 \%$ of the variance in AELEC is being explained by the RECs. Based on this we can say that the carbon prices are having very little influence on AELEC and it is the changes in AGAS that seem to have a greater influence on AELEC.

Table 2: Generalised Variance Decompositions (Jan 2004 to June 2007)

\begin{tabular}{|c|c|c|c|c|c|}
\hline Weeks & $\begin{array}{l}\text { Variable } \\
\text { Shocked }\end{array}$ & $\begin{array}{l}\text { Response of } \\
\text { AELEC }\end{array}$ & $\begin{array}{l}\text { Response of } \\
\text { NGAC }\end{array}$ & $\begin{array}{c}\text { Response of } \\
\text { REC }\end{array}$ & $\begin{array}{c}\text { Response of } \\
\text { AGAS }\end{array}$ \\
\hline & AELEC & & & & \\
\hline 0 & & 93.38 & 0.34 & 0.21 & 7.07 \\
\hline 1 & & 89.46 & 1.70 & 0.20 & 8.64 \\
\hline 3 & & 80.36 & 2.29 & 0.67 & 16.78 \\
\hline 5 & & 75.42 & 1.83 & 1.29 & 21.45 \\
\hline 10 & & 65.49 & 1.23 & 2.23 & 31.05 \\
\hline 15 & & 59.25 & 1.03 & 2.83 & 36.89 \\
\hline 25 & & 52.54 & 0.89 & 3.47 & 43.10 \\
\hline & NGAC & & & & \\
\hline 0 & & 0.36 & 99.23 & 0.11 & 0.30 \\
\hline 1 & & 0.45 & 98.32 & 0.08 & 1.15 \\
\hline 3 & & 2.16 & 95.00 & 0.07 & 2.77 \\
\hline 5 & & 2.95 & 92.49 & 0.05 & 4.51 \\
\hline 10 & & 4.72 & 88.20 & 0.04 & 7.05 \\
\hline 15 & & 5.59 & 86.11 & 0.04 & 8.27 \\
\hline 25 & & 6.37 & 84.23 & 0.05 & 9.35 \\
\hline & REC & & & & \\
\hline 0 & & 0.23 & 0.11 & 99.60 & 0.06 \\
\hline 1 & & 0.27 & 0.69 & 98.93 & 0.10 \\
\hline 3 & & 0.12 & 2.09 & 97.05 & 0.73 \\
\hline 5 & & 0.08 & 2.63 & 96.42 & 0.87 \\
\hline 10 & & 0.07 & 3.34 & 95.78 & 0.81 \\
\hline 15 & & 0.08 & 3.70 & 95.49 & 0.73 \\
\hline 25 & & 0.11 & 4.03 & 95.22 & 0.64 \\
\hline & AGAS & & & & \\
\hline 0 & & 7.09 & 0.28 & 0.05 & 93.58 \\
\hline 1 & & 12.96 & 1.57 & 0.26 & 85.20 \\
\hline 3 & & 14.76 & 2.10 & 6.50 & 76.64 \\
\hline 5 & & 18.23 & 2.48 & 8.11 & 71.18 \\
\hline 10 & & 22.94 & 2.30 & 10.02 & 64.75 \\
\hline 15 & & 26.04 & 2.08 & 10.80 & 61.07 \\
\hline 25 & & 29.38 & 1.82 & 11.52 & 57.27 \\
\hline
\end{tabular}


The output in Table 3 paints a similar picture for the minimal role that NGAC and REC play in driving variances of AELEC in the second time period. The post-2007 period shows fairly strong exogenous behaviour in all variables, with all the variance being self-explained. The dynamics between AGAS and AELEC weakens as almost $90 \%$ of the variance in AELEC is self-explained in the first 5 weeks and this only drops to $80 \%$ as we gradually move to 25 weeks out of the sample forecast period. This indicates that gas prices have a minimal impact on electricity prices on a short and long out-of-sample horizon. The AGAS prices show even higher exogeneity in which $90 \%$ of the variance is self-explained throughout the out-ofsample period. Unlike some other studies that have found a closer link between carbon prices and electricity, our study fails to establish such a link.

Table 3: Generalised Variance Decompositions (July 2007 to Dec 2010)

\begin{tabular}{|c|c|c|c|c|c|}
\hline Weeks & $\begin{array}{l}\text { Variable } \\
\text { Shocked }\end{array}$ & $\begin{array}{c}\text { Response of } \\
\text { AELEC }\end{array}$ & $\begin{array}{c}\text { Response of } \\
\text { NGAC }\end{array}$ & $\begin{array}{c}\text { Response of } \\
\text { REC }\end{array}$ & $\begin{array}{c}\text { Response } \\
\text { AGAS }\end{array}$ \\
\hline & AELEC & & & & \\
\hline 0 & & 94.95 & 0.51 & 0.05 & 4.48 \\
\hline 1 & & 94.20 & 1.53 & 0.12 & 5.16 \\
\hline 3 & & 91.46 & 3.11 & 0.69 & 4.74 \\
\hline 5 & & 90.79 & 3.07 & 1.28 & 4.86 \\
\hline 10 & & 88.36 & 3.00 & 2.44 & 6.20 \\
\hline 15 & & 86.25 & 2.94 & 3.43 & 7.38 \\
\hline 25 & & 82.34 & 2.81 & 5.27 & 9.57 \\
\hline & NGAC & & & & \\
\hline 0 & & 0.54 & 98.99 & 0.04 & 0.44 \\
\hline 1 & & 0.26 & 98.36 & 0.18 & 1.20 \\
\hline 3 & & 0.65 & 97.56 & 1.10 & 0.69 \\
\hline 5 & & 1.02 & 97.03 & 1.48 & 0.46 \\
\hline 10 & & 1.34 & 96.34 & 2.05 & 0.27 \\
\hline 15 & & 1.44 & 96.09 & 2.27 & 0.20 \\
\hline 25 & & 1.53 & 95.87 & 2.45 & 0.14 \\
\hline & REC & & & & \\
\hline 0 & & 0.05 & 0.04 & 99.89 & 0.02 \\
\hline 1 & & 0.02 & 1.40 & 98.11 & 0.47 \\
\hline 3 & & 0.08 & 1.51 & 97.81 & 0.60 \\
\hline 5 & & 0.17 & 2.64 & 96.63 & 0.56 \\
\hline 10 & & 0.51 & 3.69 & 95.40 & 0.39 \\
\hline 15 & & 0.66 & 4.09 & 94.92 & 0.33 \\
\hline 25 & & 0.77 & 4.40 & 94.54 & 0.28 \\
\hline 0 & AGAS & 4.49 & 0.42 & 0.02 & 95.07 \\
\hline
\end{tabular}




\begin{tabular}{|c|c|c|c|c|}
\hline $\mathbf{1}$ & 3.95 & 0.37 & 0.89 & $\mathbf{9 4 . 7 8}$ \\
$\mathbf{3}$ & 3.10 & 2.46 & 0.68 & $\mathbf{9 3 . 7 6}$ \\
$\mathbf{5}$ & 3.84 & 2.12 & 0.54 & $\mathbf{9 3 . 5 0}$ \\
$\mathbf{1 0}$ & 5.66 & 1.79 & 0.38 & $\mathbf{9 2 . 1 7}$ \\
$\mathbf{1 5}$ & 6.64 & 1.62 & 0.29 & $\mathbf{9 1 . 4 5}$ \\
$\mathbf{2 5}$ & 7.66 & 1.43 & 0.20 & $\mathbf{9 0 . 7 1}$ \\
\hline
\end{tabular}

inception), followed by 1 week, 3 weeks etc. Column 2; the variable which is shocked at time 0 . Column 3 - 6; these measure the response in the price of the variable (column 3 AELEC etc. as indicated) to the shock in the variable in column 2, it indicates how much (percentage) change in its price occurs due to the shock immediately $(\mathrm{t}=0)$ and then after the number of weeks indicated in column1.

The information contained in the GVDs can be equivalently represented by graphs of the generalised impulse response functions. We break the impulse response function analysis into two elements, with Figures 5 and 6 looking at the impact of a shock in each individual variable and the response profile of the entire cointegrating vector. This approach, although available in standard econometric packages like Microfit 5.0, is not readily utilised but interesting results could be obtained to see if a single variable has an important bearing on the entire system (i.e. the cointegrating vector). The upper and lower bounds show the bootstrap confidence interval of impulse responses at the 95\% confidence level. This helps us gauge which variable causes a bigger impact on the system as a whole even though this is not captured in the GVDs.

In Figure 5 shocks to electricity prices initially have a downward impact on the cointegrating vector but within a few weeks prices tend to increase before declining and then ultimately reaching a steady state equilibrium after approximately 14 weeks out of sample. In Figure 6, shocks to AELEC have a sharp negative impact and then decrease further and reach a steady state much faster than in Figure 5. These findings could be interpreted as meaning that electricity prices had a bigger impact on the cointegrated system prior to 2007 with no positive impacts between 2007 and 2010. Similar movements are observed with shocks to NGAC prices. As shown in Figure 5, initially there is a positive impact on the cointegrating vector and then the system gradually continues on a downward path with some persistence 
before returning to equilibrium after approximately 14 weeks out of sample. In Figure 5 the shock from NGAC is vastly different, with the remaining prices collectively declining and staying below “zero” for approximately 2 weeks and then returning to equilibrium in about half the time (approximately 7 weeks) in comparison to shocks in electricity prices. This tells us that in the latter half of the sample NGAC prices did not have a huge bearing on the dynamics of the estimated model. Another interesting observation from Figures 5 and 6 is that overall the system takes 14 weeks to reach equilibrium in the 2004-2007 period and approximately 7 weeks in the $2007-2010$ period. This illustrates that in recent times, shocks to electricity and emission trading scheme prices tend to cause only minor distortions in the very short run before settling to a steady state equilibrium.

Figure 5: Impulse Response Functions of the cointegrating vector to shocks in individual variables (Jan 2004 - June 2007).

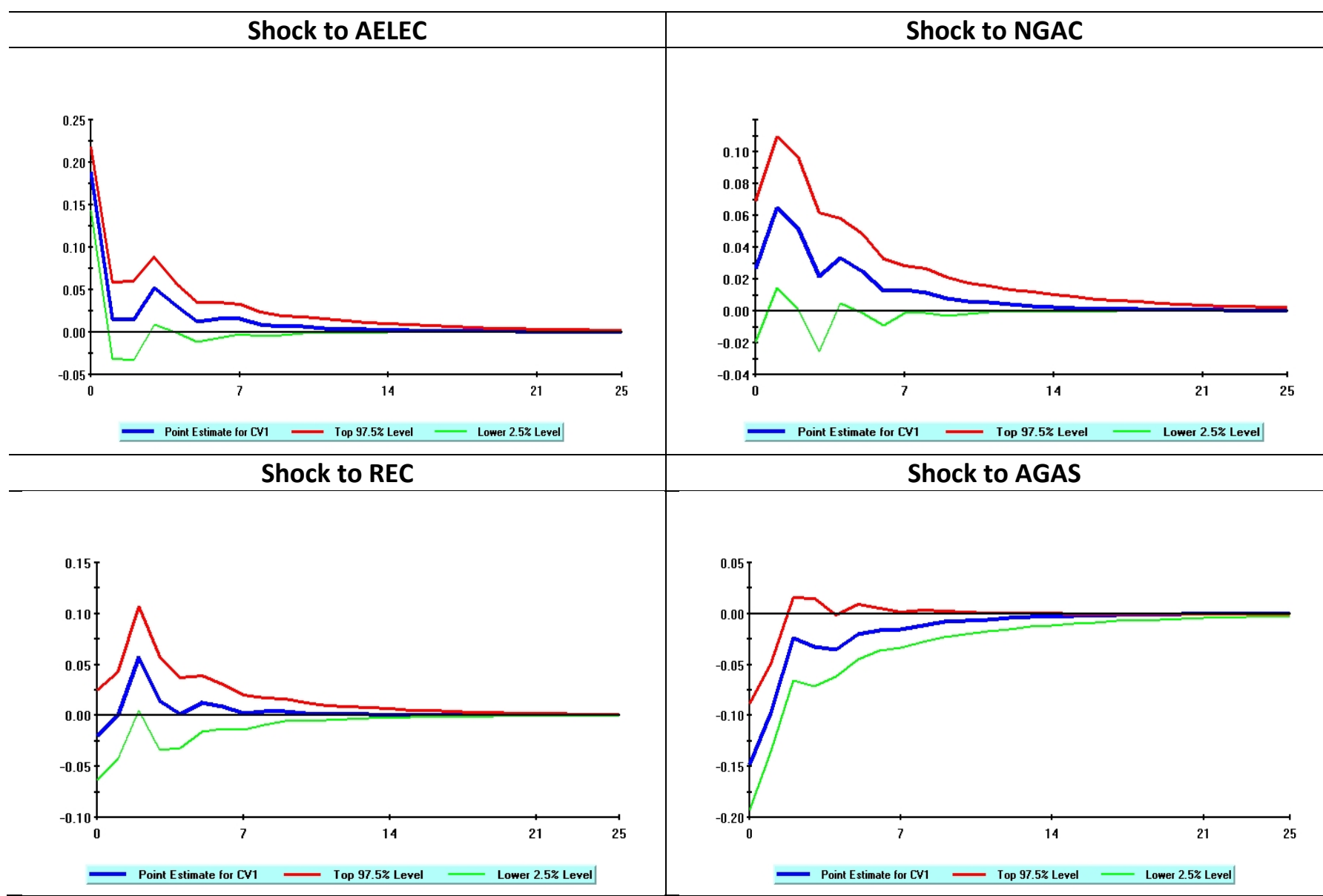


Figure 6: Impulse Response Functions of Cointegrating Vectors to shocks in equation (July 2007 to Dec 2010)

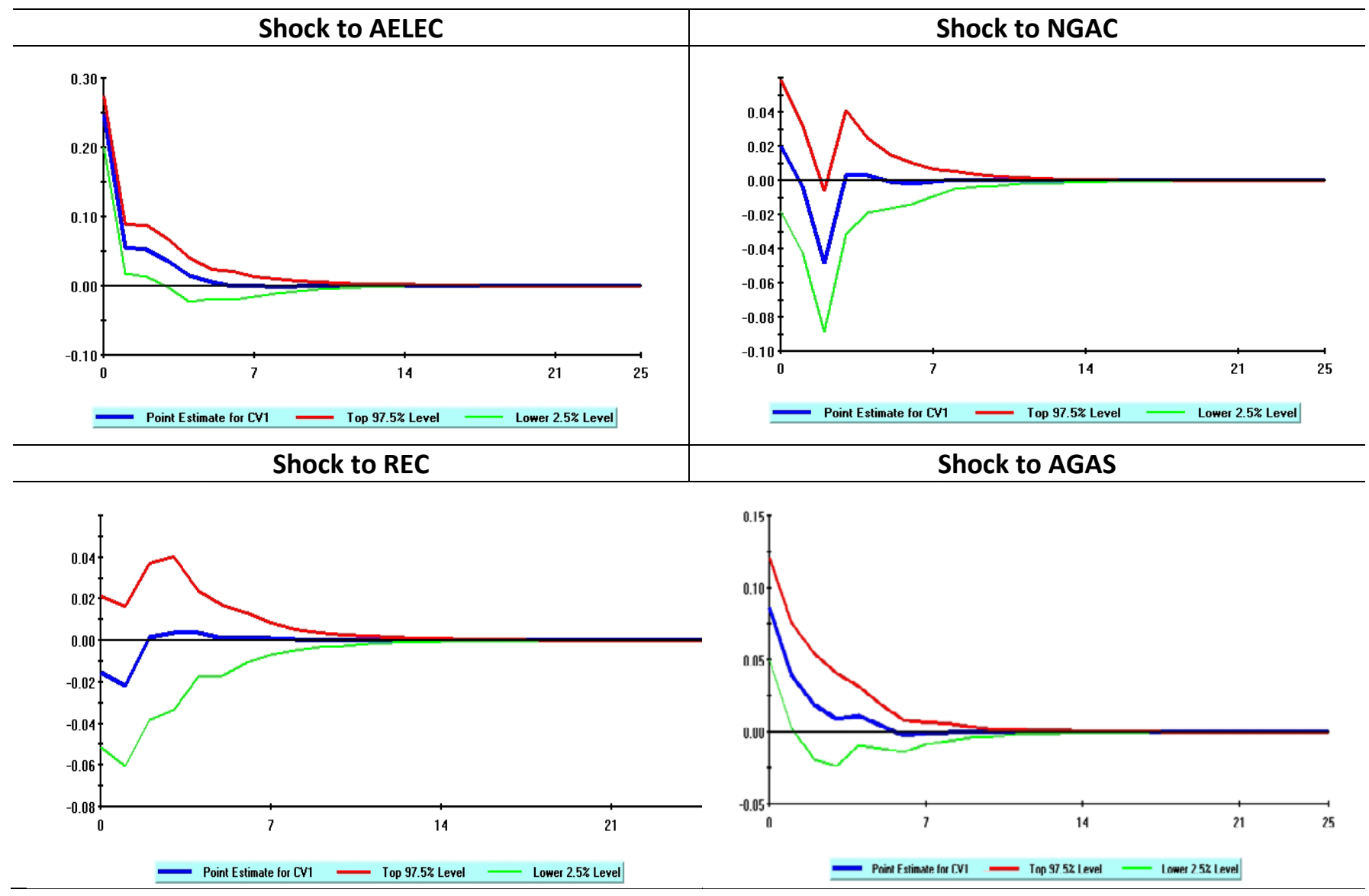


Figures 7 and 8 show the dynamic response of each variable when a one standard deviation shock is introduced in each of the residuals of the variables. For example, in the upper left panel of Figure 7, we can see that “own” shocks to AELEC die out quickly but prices reach a higher steady state equilibrium, indicating an increasing cost of electricity. The impact is almost 'zero' on the rest of the variables and this is supported by the small role that AELEC plays in explaining the forecast error variance of other variables shown by the results in the GVDs. Shocks to NGAC do however have some impact on AELEC but they return to "zero" within 3.5 weeks and then continue on a downward trajectory before settling at an equilibrium below 'zero'. Shocks to AGAS have lasting positive effects on AELEC which is not surprising given the strong association between the two during the first sample period. This however is not the case in Figure 7 where shocks to AGAS do not feed through to AELEC but rather AGAS prices reach a higher steady state equilibrium.

In Figure 7, “own” shocks to NGAC and REC tend to cause lasting effects on their own prices (they settle at a much higher steady state) with very minimal impact on other variables. This is supported by the exogeneity shown by NGAC and REC in error correction results together with the out-of-sample exogeneity found in the GVDs analysis. Similar to results in Figure 5, shocks to AELEC die out very quickly and all other prices (the combined effect is captured in Figure 5 by the response of the cointegrating vector) return to equilibrium in approximately 7 weeks.

Figure 7: Impulse Responses Functions of Individual Variables to shocks in equation (Jan 2004 to June 2007) 


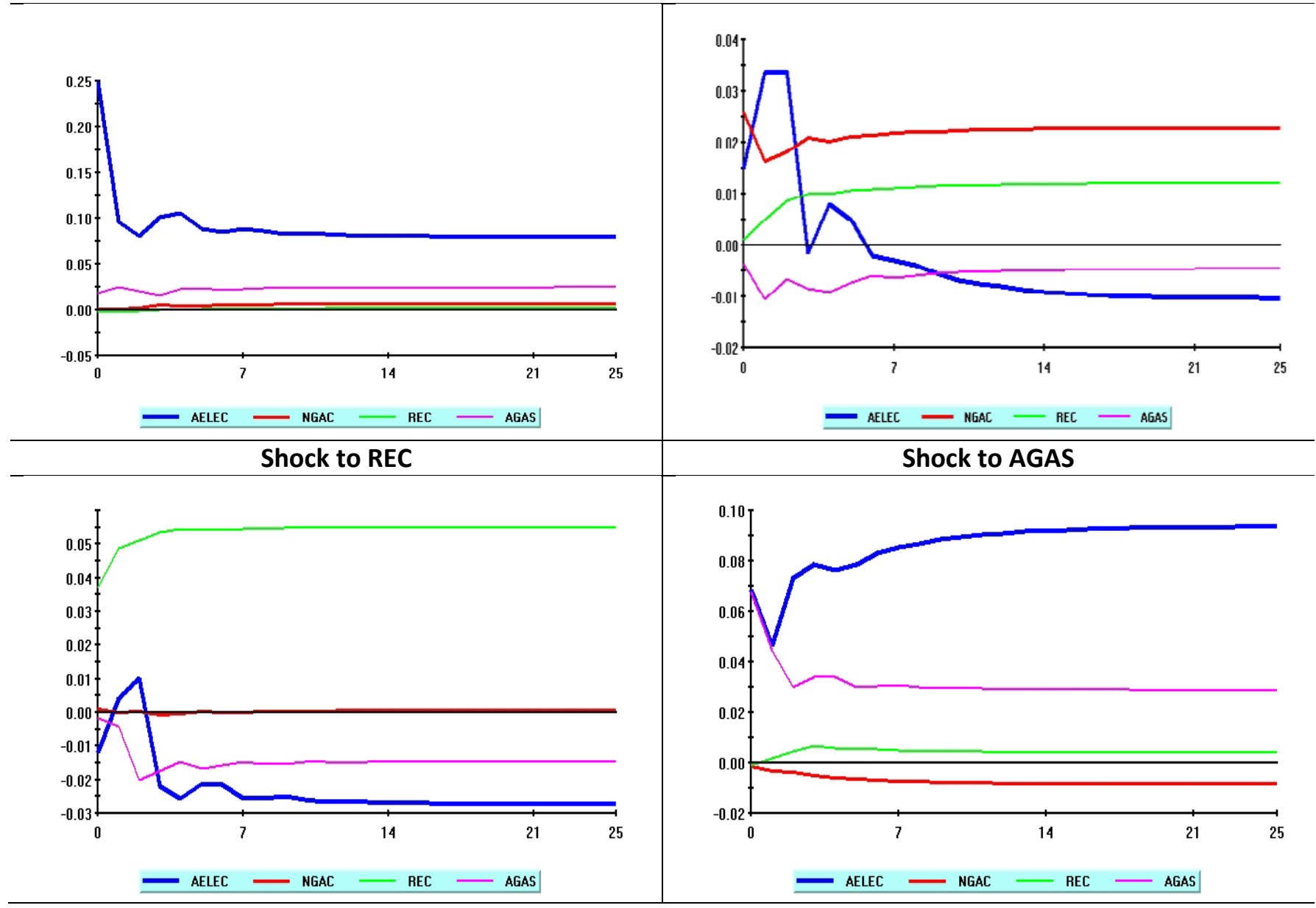

Figure 8: Impulse Responses Functions of Individual Variables to shocks in equation (July 2007 to Dec 2010)

Shock to AELEC
Shock to NGAC




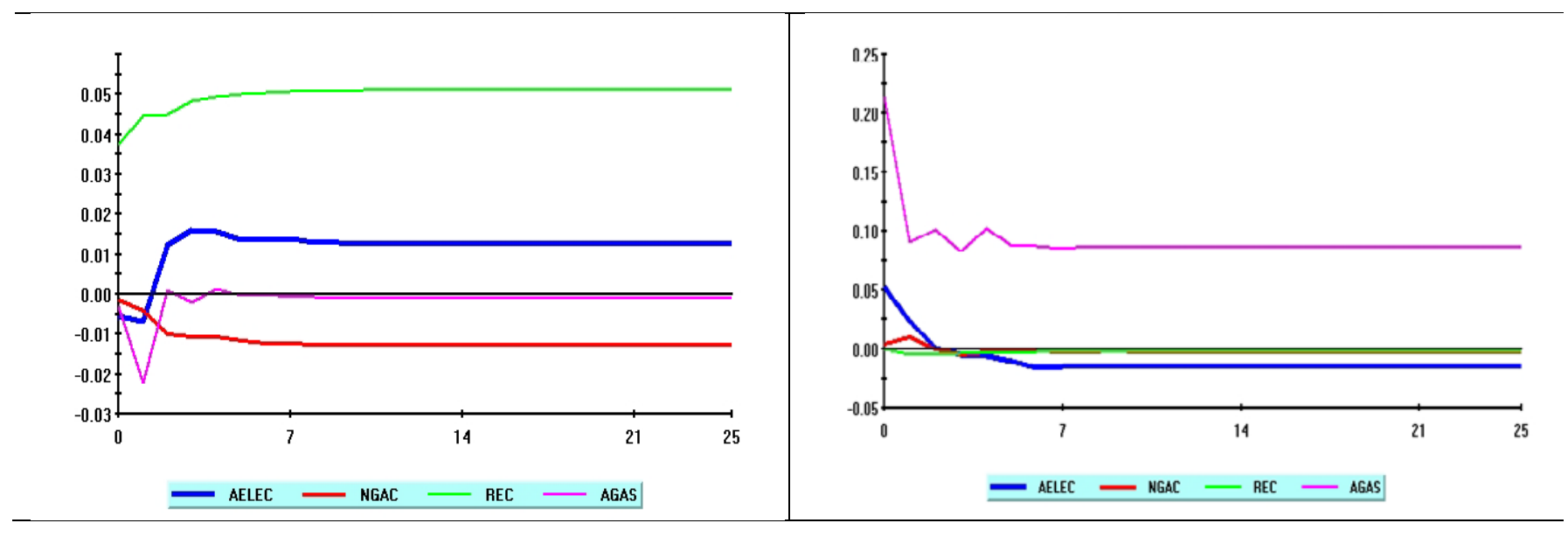




\section{Discussion}

Much of the initial analysis undertaken is similar to earlier studies of the relationship between carbon prices and electricity prices in Australia and internationally. In this paper we are testing for a long-term relationship as was done by Bunn and Fezzi (2007) and others, and as is discussed in the literature section, Section 2.1. The LSRM methods used may be inconclusive when autocorrelation is present which is highly likely when using time series data. Zachmann and von Hirschhhausen (2008) and others improved on earlier studies and addressed the problems of autocorrelation by using ECM and VECM and this forms the initial part of our analysis. We find that while we can see that electricity is adjusting to its long-run equilibrium we want to determine in this paper which variable/s is/are forcing this to occur. In our early analysis it appears to be the electricity itself. We use GIRFs and GVDs for the first time on this type of market and they provide us with an understanding of the relative exogeneity or endogeneity of the variables. A shock to the variance of one of the variables is introduced so that we are able to see if electricity is driven by these other variables. This methodology enables a better understanding of which variables play a role. The GIRFs determine how the shocks given to the residuals impact on each of the variables. Here we can determine how long the effects of the shocks last and as such the importance of the long-term effect of each variable on the prices of the other variables. The findings, as shown in Section 3 above, give a first clear insight of how short term the effect is of shocks by the other variables on electricity prices. As discussed in the conclusion, the indication is that neither of the schemes has had significant effect on the electricity prices.

These results provide some empirical evidence to endorse earlier research which suggests some problems with Australia’s emissions trading schemes. Griffiths et al. (2007) note the climate change conflicts in Australian policy that are caused by differing targets set individually by the states and federal governments. In line with our earlier discussion they 
state that 'green and other environmental groups have been marginalized as large corporations seek to influence the design and structure of any carbon tax or emissions trading scheme'. Further they conclude that 'part of the resilience of the coal industry in Australia has been its effective ability to lobby governments to attract resources and desirable policy outcomes.' The results of this lobbying may provide some understanding of the results we find in this paper. Further evidence of the lack of any long-term relationship can be seen in the Department of the Environment National Inventory (Australian Government, 2012c). In this report the authors state that electricity generation emissions increased by $49 \%$ from 1990 to 2012. In the period 2009-2010, during the second period of our analysis in this paper, the report shows a slight decrease in the $\mathrm{CO}_{2}$ emissions from coal for electricity generation by fossil fuels. It is worth understanding though that in 2012 around $90 \%$ of all coal consumed in Australia was used for electricity generation.

When looking at the MRET and GGAS we tend to see parallels with the EU ETS which is by far the larger and more highly traded scheme. Ellerman and Buchner (2007) explain that when the emissions data were released in Europe in April and May 2006, they revealed that the allowances for emissions exceeded the actual emissions by around 80 million tons or four per cent of the EU ETS cap. This revelation of the over-allocation of allowances explains the fall of EUA prices at this time. Not all countries who were participants in the EU ETS, and not all sectors covered by the scheme, were over-allocated. However, the overall effects of the price fall, and the resulting increase in uncertainty and concern, were widespread. This type of uncertainty may also be contributing to the lack of impact on electricity prices by the Australian emissions trading schemes analysed in this paper.

\section{Conclusion and Policy Implications}


This paper captures the dynamics between the price of electricity, the NSW greenhouse gas abatement certificates, the mandatory renewable energy certificates and the price of natural gas. Our findings show that there is a long-term relationship between the variables in both the samples. On further analysis however, the short run-dynamics indicate that NGAC and REC play a minimal role in explaining movements in electricity prices. The interactions between NGAC and electricity are stronger in the first half of the sample but then dissipate in the second period. This paper has separated the ETSs from other policies and has found that neither the GGAS or MRET certificates affect the electricity prices. So even though compliance requirements were met for both schemes during the period under analysis, schemes appear to have been ineffective in attaining their main goals. While these results differ from earlier studies in Australia, and most international scheme analysis, there are other indications that vindicate our findings. The continued high level of use of coal as an energy source in Australia indicates little to no actual change to lower emission alternatives. Because of coal's importance to Australia's export income, both of the major political parties have failed to introduce policies which increase green energy and reduce the use of coal. While we do see in our results in the first time period an effect of gas prices on electricity prices, the proportion of gas relative to coal as a fuel source in Australia has not increased significantly. Our findings indicate that a policy requiring a greater proportion of green energy as a source of energy production will be required before the carbon price will affect the electricity price. The introduction of the carbon price on July 1, 2012 may have provided the required change, however the new federal government has introduced legislation to cease the operation of this carbon price. Where Australian policy goes from here, and the likelihood of it legislating for greater use of green energy, is as yet unknown.

\section{References}


Akaike, H., 1974. A new look at the statistical model identification. IEEE Transactions on Automatic Control 19), 716-723.

Australian Bureau of Statistics, 2013. 5368.0 International trade in goods and services, Australia, Jun, 2013, Retrieved 30/08/13.

http://www.abs.gov.au/AUSSTATS/abs@.nsf/DetailsPage/5368.0Jun\%202013?OpenDocum $\underline{\text { ent\#Publications }}$

Australian Government, 2012. Australian greenhouse accounts, quarterly update of Australia’s National Greenhouse Gas Inventory, December Quarter 2012, Department of Climate Change and Energy Efficiency. Retrieved 16/6/14. http://www.environment.gov.au/system/files/resources/6b894230-f15f-4a69-a50c5577fecc8bc2/files/national-inventory-report-2012-vol1.pdf

Australian Government, 2011. Department of Resources, Energy and Tourism, Energy in Australia 2011, Retrieved 16/8/12.

http://adl.brs.gov.au/data/warehouse/pe_abares99001789/Energy_in_Aust_2011_13f.pdf

Australian Industry Group, 2011. Energy shock: confronting higher prices, Retrieved 17/8/12. http://www.aigroup.com.au/portal/binary/com.epicentric.contentmanagement.servlet.Content DeliveryServlet/LIVE_CONTENT/Publications/Reports/2011/Energy_shock_confronting_hi gher_prices.pdf

Bertrand, V., 2012. Interactions between carbon and energy prices: theories and evidence in Phase 2 of the EI ETS. Working Paper: University of Franche-Comté, CRESE 
Bunn, D. W., Fezzi, C., 2007. Interaction of European carbon trading and energy prices. FEEM Working Paper No. 63.2007. doi.org/10.2139/ssrn.993791

Bunn, D.W., Fezzi, C. 2009. Structural interactions of European carbon trading and energy prices, J. of Energy Markets 2, 53-69.

Bureau of Resources and Energy Economics, Australian Government, 2012. Australian energy technology assessment, Retrieved 13/8/13.

http://www.bree.gov.au/publications/aeta.html

Cotton D., Trück S., 2011. Interaction between Australian carbon prices and energy prices. Australasian Journal. of Environmental Management 18, 208 - 222

Daley, J., Edis, T., 2011. Learning the hard way: Australia’s policies to reduce emissions, Grattan Institute Report No. 2011 - 2 April 2011.

Department of Climate Change and Energy Efficiency, 2011. Renewable energy target. Retrieved 30/8/12.

http://www.climatechange.gov.au/government/initiatives/renewable-target.aspx

Dickey, D., Fuller, W., 1979. Distribution of the estimator for autoregressive time series with a unit root. Journal of the American Statistical Association 74, 427-431. 
Ellermanm A.D., Buchner B.K., 2007. The European Union Emissions Trading Scheme: origins, allocation and early results, Rev. of Environmental Economics and Policy. 1, 66-87.

Enerdata, 2013. Global energy statistical yearbook 2013, Retrieved 30/08/13.

http://yearbook.enerdata.net/

Fama, E.F., 1970. Efficient capital markets a review of theory and empirical work, J. of Finance 25, $383-417$.

Fama, E.F., 1998. Market efficiency, long-term returns and behavioural finance. J. of Financial Economics 49, 283 - 306.

Freitas, C.J.P., da Silva, P.P., 2013. Evaluation of dynamic pass-through of carbon prices into electricity prices - a cointegrated VECM analysis. Int. J. Public Policy 9, 65 - 85.

Garnaut R., 2011. Climate change review 2011 “update 2011”. Chapter 11 http://www.garnautreview.org.au/update-2011/garnaut-review-2011/chapter11.html

Granger, C. W. J., 1969. Investigating causal relations by econometric models and crossspectral methods. Econometrica 37 424-438

Griffiths, A., Haigh, N., Rassias, J., 2007. A framework for understanding institutional governance systems and climate change: the case of Australia. European Management J., 25, 415-427 
Honkatukia, J., Mälkönen, V., Perrels, A., 2006. Impacts of the European Emission Trade System on Finnish wholesale electricity prices. Discussion Papers 405, Government Institute for Economic Research Finland (VATT).

Johansen, S., 1991. Estimation and hypothesis testing of cointegration vectors in Gaussian autoregressive models. Econometrica 59, 1551-1580.

Johansen, S., Juselius, K., 1990. Maximum likelihood estimation and inference on cointegration: with application to the demand for money. Oxford Bulletin of Economics and Statistics. 52, 169-210.

Jouvet, P., Solier, B., 2013. An overview of $\mathrm{CO}_{2}$ cost pass-through to electricity prices in Europe. Energy Policy. 61, 1370-1376

Kara, M., Syri, S., Lehtila, A., Helynen, S., Kekkonen, V., Ruska, M., Forsstrom, J., 2008. The impacts of EU $\mathrm{CO}_{2}$ emission trading on electricity markets and electricity consumers in Finland. Energy Economics. 30, 193 - 211.

Keppler, J.H., Mansanet-Bataller, M., 2010. Causalities between $\mathrm{CO}_{2}$ prices, electricity and other energy variables during phase I and phase II for the existence of the EUA-sCER spread. Energy Policy.39, 1056-1069.

Koop, G., Pesaran, M.H., Potter, S.M., 1996. Impulse response analysis in nonlinear multivariate models, J. of Econometrics. 74, 119-147. 
Kwiatkowski, D., Phillips P., Schmidt P., Shin Y., 1992. Testing the null hypothesis of stationarity against the alternative of a unit root: How sure are we that economic time series have a unit root? J. of Econometrics. 54, 159-178.

Nelson, T., Kelly, S., Orton, F., 2012. A literature review of economic studies on carbon pricing and Australian wholesale electricity markets. Energy Policy. 49, 217 - 224

Neuhoff, K., Martinez, K. K., Sato M., 2006. Allocation, incentives and distortions: the impact of EU ETS emissions allowance allocations to the electricity sector. Climate Policy. 6, $73-91$.

Oberndorfer, U., 2009. EU emission allowances and the stock market: evidence from the electricity industry. Ecological Economics. 68, 1116-1126.

Pesaran, B., Pesaran, H., 2009. Time series econometrics using Microfit 5.0. Oxford University Press, Oxford.

Pesaran, M. H., Shin, Y. S., 2002. Long-run structural modelling. Econometric Reviews. 21, 49-87.

Phillips, P., Perron P., 1988. Testing for a unit root in time series regression. Biometrika. 75, 335-346.

Pinho, C., Madaleno, M., 2011. CO2 emission allowances and other fuel markets interaction. Environmental Economics and Policy Studies. 13, 259 - 281. 
Sartzetakis, E. S., 2004. On the efficiency of competitive markets for emission permits.

Environmental and Resource Economics. 27, 1 - 19.

Sims, C., 1982. Macroeconomics and reality. Econometrica. 48(1), 1-48.

Sjim J., Neuhoff, K., Chen, Y., 2006. $\mathrm{CO}_{2}$ cost pass through and windfall profits in the power sector. Climate Policy. 6, 49 - 72.

Zachmann, G., Von Hirschhausen, C., 2008. First evidence of asymmetric cost pass-through of EU emission allowances: Examining wholesale electricity prices in Germany. Economic Letters 99, 465 - 469. 